\title{
DEVELOPMENT OF FRAMEWORK FOR SEISMIC RESPONSE ANALYSIS OF STORAGE TANK BASED ON FAULT - STRUCTURE SYSTEM
}

\author{
Tilak Pokharel $^{1}$, Tsuyoshi Ichimura ${ }^{2}$, \\ Muneo Hori ${ }^{2}$, Toshio Nagashima ${ }^{3}$ \\ ${ }^{1}$ CEO, GHEaSES International, Nepal \\ ${ }^{2}$ Professor, The University of Tokyo, Japan \\ ${ }^{3}$ Professor, Sophia University, Japan
}

\begin{abstract}
In this study, the framework for the seismic response analysis of oil-storage tank along fault-structure system concept has been presented; where the long period ground motion simulation and sloshing simulation based on 3D finite element method (FEM) is integrated. Three dimensional finite element model is constructed using multi-resolution structured and unstructured mesh for the ground motion prediction. For the sloshing analysis Lagrangian Finite Element Method is used. Also the effect of surface topography on the sloshing response is checked and the effect is found to be significant.
\end{abstract}

Keywords: earthquake response, long period ground motion, FEM, storage tank.

\section{Introduction}

The seismic performance of an oil-storage tank has been of particular interest since its failure may cause a great disaster. In 2003 Tokachi-Oki earthquake the oil tanks in and around Tomakomai area were severely damaged. Similar instances of damage could be seen in 1964 Nigata earthquake, 1983 Nihonkai-Chubu earthquake, 1993 Southwest-Off Hokkaido earthquake, 1994 Alaska earthquake (US A), 1999 Koceaeli earthquake (Turkey), 1999 Chi-Chi earthquake (Taiw an) and so on [Zama et al (2008)].

To reduce the earthquake disaster we need to know the seismic behavior of such structures accurately for probable large earthquakes. For the accurate estimation of sloshing phenomenon we need the ground motion caused by the site-specific earthquake.

*Corresponding author: Tilak Pokharel

CEO, GHEaSES International, Nepal

Email:pokhreltilak@gmail.com

(Received: 2013 Jan 08 Approved: 2013 May 02)
Earthquake ground motion simulation usually neglects the effect of surface topography. But recent researches show that the effect of surface topography has significant effect on earthquake ground motion distribution [Ma et al (2006), Lee et al (2009), Pokharel et al (2011)]. Thus, we use 3D FEM for the ground motion simulation, which can handle the complicated surface and interface geometry.

In general, the structural seismic response is a consequence of the following processes: the rupture of a fault, propagation of earthquake waves through the crust, amplification of the waves near the ground surface, and soil-structure interaction. A complete model for all of these processes is a fault-structure system, and must include a fault, crust structure, surface ground layers, and target structures. One of the candidates for analyzing such fault-structure system is three-dimensional (3D) numerical simulation. With the advancement of computational technology and development of 3D soil and crust structure, we can create fairly complex and more realistic models and do 3D numerical simulations with higher accuracy and resolution. There are several 
researches on seismic structural response simulations based on 3D numerical simulation along faultstructure system concept (e.g. Ichimura et al (2012)).

The content of this article include the following: first in methodology section, outline of long period ground motion simulation and sloshing simulation is presented. After that, in numerical experiment section, long period ground motion simulation and sloshing response of Akita oil storage tank is presented.

\section{Methodology}

For the ground motion simulation a 3D FEM is used. This method solves the problem by generating a hybrid mesh to handle the complicated geometry using structured and unstructured tetrahedral and cubic elements to handle the complicated surface and interface geometry.

In this study, 3D FEM based on elastodynamics is used. The working equation is derived by discretizing in space by Galerkin's method and in time by Newmark- $\beta(\beta=1 / 4)$ method with a Rayleigh damping term added

$$
\begin{aligned}
& \left(\mathbf{K}+\frac{2}{t} \mathbf{C}+\frac{4}{t^{2}} \mathbf{M}\right) \mathbf{u}^{n+1}= \\
& \left(\frac{2}{t} \mathbf{C}+\frac{4}{t^{2}} \mathbf{M}\right) \mathbf{u}^{n}+\left(\mathbf{C}+\frac{4}{t} \mathbf{M}\right) \mathbf{v}^{n}+\mathbf{M a}^{n}+\mathbf{f}^{n}
\end{aligned}
$$

Therein, $\mathbf{K}, \mathbf{C}, \mathbf{M}, \mathbf{u}, \mathbf{v}, \mathbf{a}, \mathrm{f}, \Delta \mathrm{t}$ and $\mathrm{n}$ are the stiffness matrix, damping matrix, mass matrix, displacement vector, velocity vector, acceleration vector, force vector, time increment and time step respectively. Rayleigh damping model is used to calculate the damping matrix.

$$
\mathbf{C}=\mathbf{K}+\mathbf{M}
$$

Therein, $\alpha$ and $\beta$ are the scalar constant and calculated as in, Bielak (2006).

Since the size of target domain is larger and the resolution of discretization is finer, the computation cost of the modeling and simulation will be huge. To reduce this computation cost, we use highly-tuned FEM [Ichimura et al (2009)]. This FEM solves the problem 1) by generating a hybrid mesh to handle the complicated geometry using multi-resolution cubic elements and unstructured tetrahedral elements for modeling and 2) by applying element-by-element method and conjugate gradient method to the solver.

For the sloshing analysis, we use 3D FEM based on the fluid-structure coupling analysis method, where the Lagrange-type and the Euler-type finite element formulations are utilized for structure and fluid modeling, respectively [Nagashima and Tsukuda, 2010].

\section{Numerical Experiment}

In this section, as an application example, we conduct the response analysis of Akita oil storage tank (located at the northern part of Honsu island, Japan) in the past-observed earthquake that occurred in the Akita region on 2008/06/14 with magnitude of M7.2 epicenter at $\left(39.0298^{\circ} \mathrm{N}, \quad 140.8807^{\circ} \mathrm{E}\right)$. This application example includes the earthquake ground motion simulation and sloshing simulation.

Firstly, the simulation of long period ground motion distribution is conducted. The analysis domain is $120 \mathrm{~km} \times 120 \mathrm{~km} \times 100 \mathrm{~km}$ in EW, NS and UD direction respectively. The analysis domain is presented in Fig 1 where target domain is depicted by dotted line, earthquake epic enter by star, observation stations by triangles and location of oil-tank by circle with cross. The mechanism solution is estimated by F-NET. The crust structure is obtained from J-SHIS which consists of 10 layers. The element size is set such that the shear wavelengths corresponding to target frequency are resolved with 10 elements per one wavelength. The target frequency is set at $0.25 \mathrm{~Hz}$ and band-pass filter is applied to remove the frequency components except [0.0-0.25] Hz. Fig 2 shows the close up view of the generated mesh. The analysis is done using time increment of $0.01 \mathrm{sec}$ for the target duration of $81.92 \mathrm{sec}$. Absorbing boundary conditions are applied at the side and bottom of the domain to implement the infinite extent of domain. Fig 3 shows the comparison of calculated and observed waveforms at one of the K-NET observation station in EW, NS and UD component. As can be seen in the Fig, amplitude and phase property are reproduced with comparatively good accuracy. 


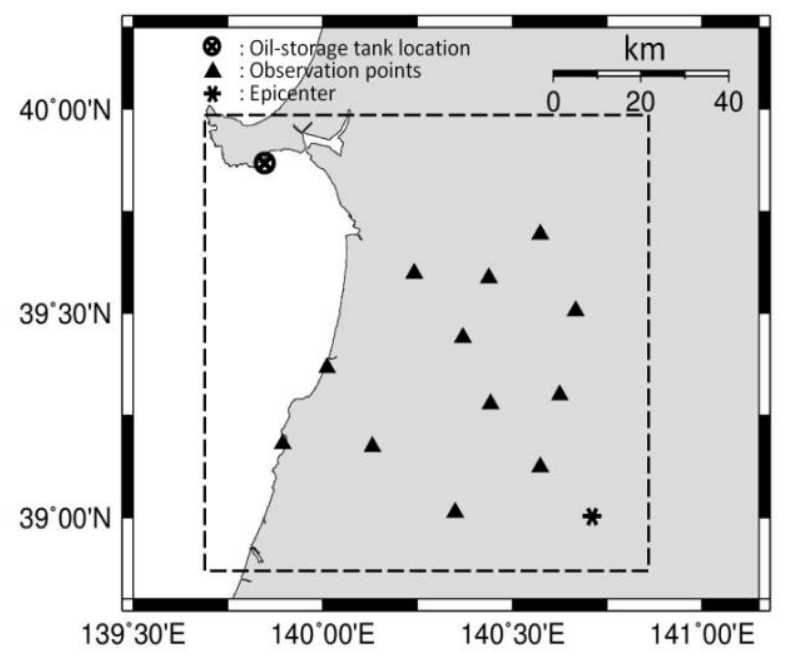

Fig 1 Analysis domain. Dashed line, star, black triangle and circle with cross represents the analysis domain, epicenter of earthquake, observation locations and location of oil tank respectively.

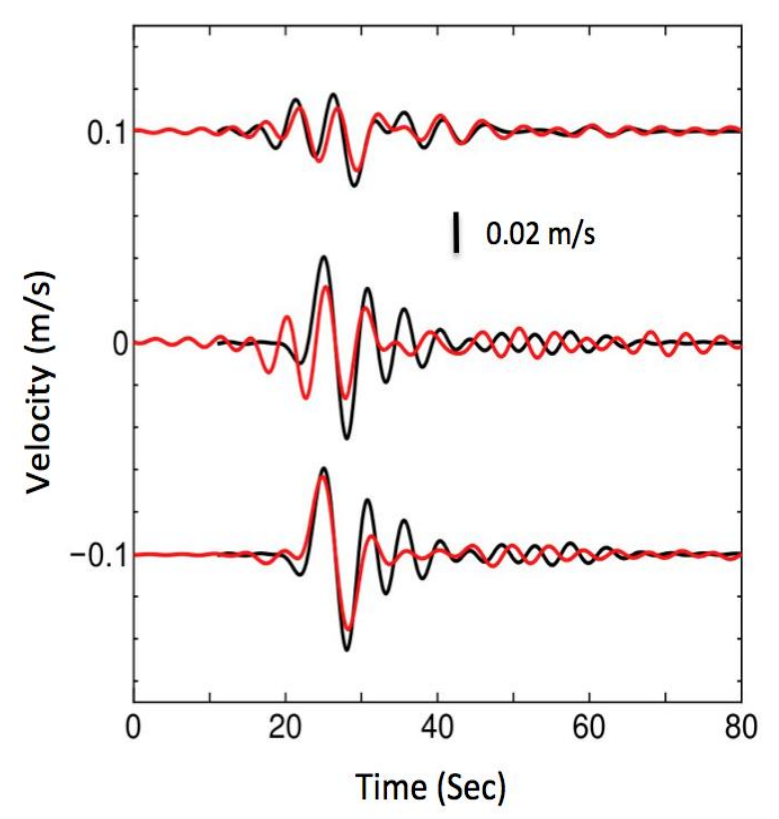

Fig 3 Velocity time series of a K-NET station, at EW (lower), NS (middle), and UD (upper) components in $\mathrm{m} / \mathrm{s}$, where black line represents the observed data and red line represents the synthetic data. The horizontal axis is the time in seconds.

The seismic response analysis of oil storage tank is conducted by using the ground motion simulation result for Akita earthquake obtained in previous section. Here, the time history of acceleration is used for the external excitation. We construct a fictitious

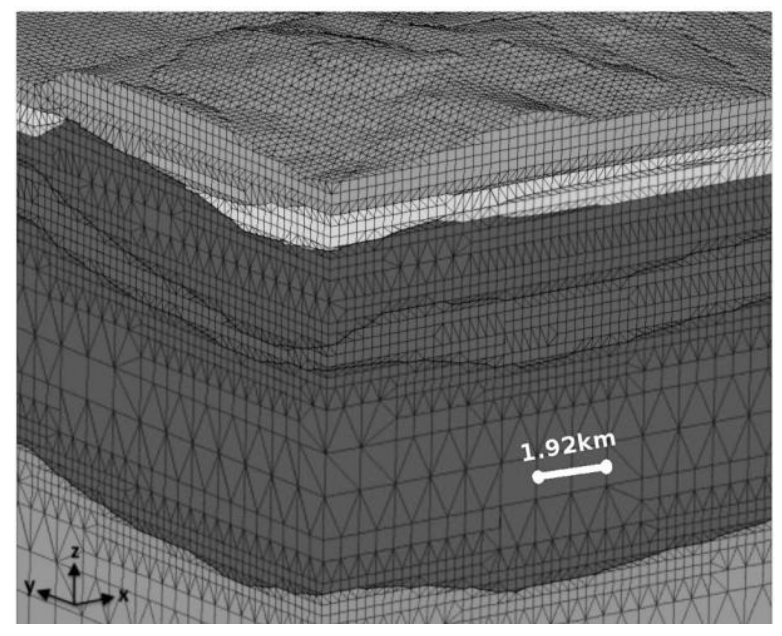

Fig 2 Close up view of generated mesh, which shows the hybrid mesh generated for the analysis to handle the complicated geometry of real topography of the analysis region.

3D FEM model for storage tank as shown in Fig 4, which is equivalent to existing tank. The storage tank model resembling the actual size of 100,000-kiloliter class stockpiled floating roof type oil storage tank with single deck is used in the analysis. The tank has an internal radius of $40 \mathrm{~m}$ and height of $25 \mathrm{~m}$. Liquid level of the tank is $20 \mathrm{~m}$ from the bottom of the tank. The tank material is steel and thickness at bottom is $9 \mathrm{~mm}$ and wall thickness is $14 \mathrm{~mm}$. The maximum sloshing height is calculated caused by the abovementioned earthquake. The maximum sloshing height obtained from this analysis is $18.85 \mathrm{~cm}$, which is very close to the observed height. Here, the sloshing height is calculated for two cases viz, with considering the surface topography and flat surface approximation. The maximum sloshing height considering the surface topography is found to be more than $20 \%$ greater than that of flat surface approximations.

\section{Conclusions}

We present a framework for estimation of sloshing response in an earthquake which integrate ground motion simulation and sloshing simulation based on 3D FEM so that we can obtain the result with higher accuracy. As an application example, earthquake ground motion simulation of the observed earthquake is conducted and the computed wave profiles are compared with the observed wave profiles. 

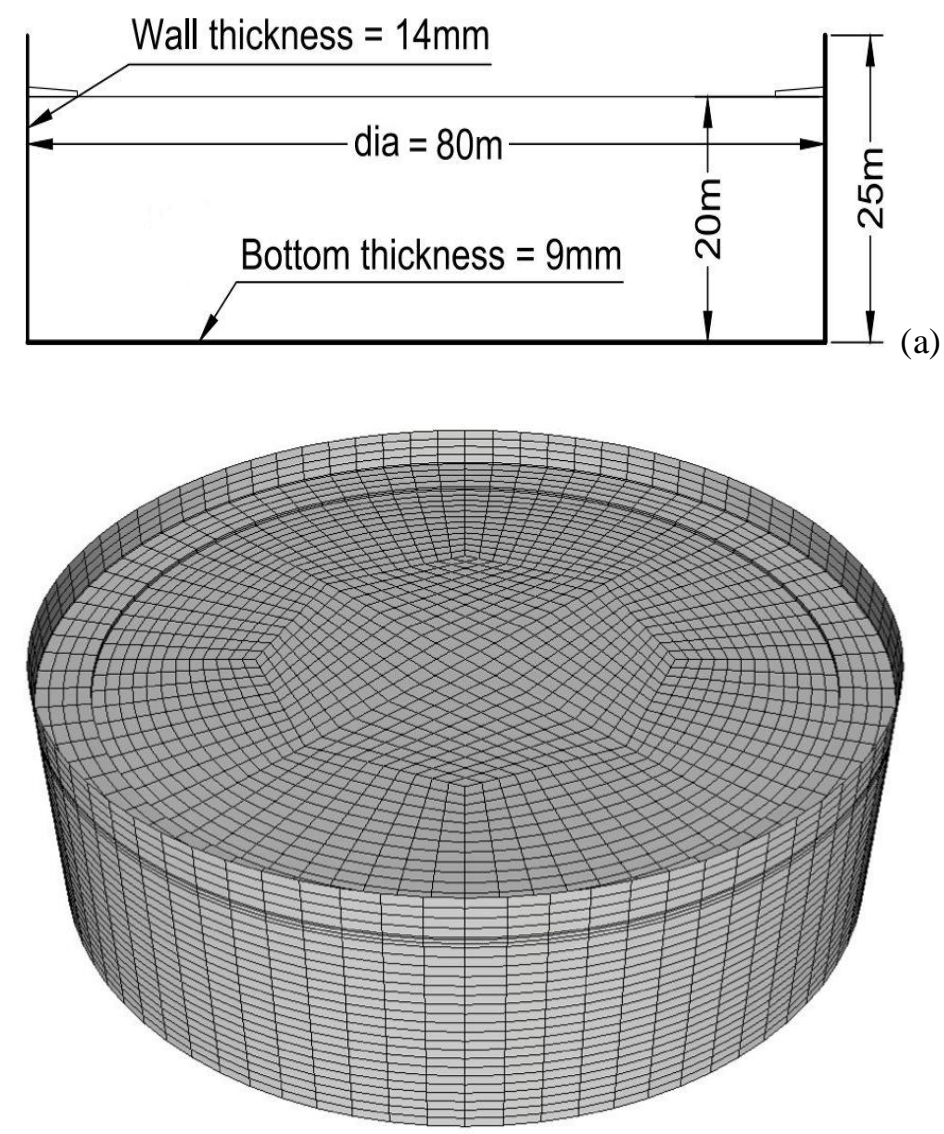

(b)

Fig 4 Dimension (a) and FEM mesh (b) of single deck floating roof type oil-storage tank used in this study, which resembles the actual size of 100,000-kiloliter class stockpiled storage tank.

After checking the closer agreement between the observed and the computed wave profiles, we conduct the seismic response of Akita oil-storage tank in that observe earthquake.We also check the effect of surface topography on the sloshing response of Akita oil tank. Although in this particular case of a small earthquake, the difference in sloshing height with/without considering the surface topography is not large, the effect is expected to be significant in case of large earthquakes. In the next step, we are planning to conduct seismic response analysis of oil tank in large earthquake using our framew ork.

\section{Acknowledge ment}

We acknowledge the K-net, F-net and J-SHIS for providing the observed data, mechanism solution for the earthquake and crust structure respectively. We also acknowledge the Ministry of Education, Culture, Sports, Science and Technology, Japan for providing the financial help to conduct this research.

\section{References}

[1] Bielak, J., Ghattas, O., and Kim, E. (2006). Parallel octree-based finite element method for large scale earthquakeground motion simulation. Computer Modeling in Engineering and Sciences, pp .99-112.

[2] Ichimura T., Hori M., Quinay P. E., Wijerathne M. L. L., Suzuki T. and Noguchi S. (2012) Comprehensive numerical analysis of fault-structure systems Computation of the large-scale seismic structural response to a given earthquake scenario, Earthquake Engineering \& Structural Dynamics, 41(4), 795-811.

[3] Ichimura, T., Hori, M., and Bielak, J. (2009). A hy brid multi-resolution meshing technique for finite element three-dimensional earthquake ground motion modeling in basins including topography. Geophysical Journal International, 177(3):1221-1232.

[4] Lee, S. J., Komatitsch, D., Huang, B. S., and Tromp, J. (2009). Effects of topography on seismic-wave propagation: An example from northern Taiwan. Bulletin of the Seismological Society of America, 99(1): 314-325.

[5] Ma, S. and Liu, P. (2006). Modeling of the perfectly matched layer absorbing boundaries and intrinsic 
attenuation in explicit finite-element methods. Bulletin of the Seismological Society of America, 96(5):17791794.

[6] Nagashima, T. and Tsukuda, T. (2010). Seismic response analysis of an oil storage tank using Lagrangian fluid finite elements, $7^{\text {th }}$ ACEE International Workshop.

[7] Pokharel, T., Quinay, P. E. B., Ichimura, T., and Hori, M. (2011). Preliminary discussion of surface topography effect on long period ground motion distribution in Kanto region. Proceedings of the Thirtheenth International Summer Symposium, pp 5962.

[8] Zama, S., Nishi, H., Yamada, M., and Hatayama, K. (2008). Damage of oil storage tanks caused by liquid sloshing in the 2003 tokachi oki earthquake and revision of damage spectra in the long period range. The 14th World Conference on Earthquake Engineering. 